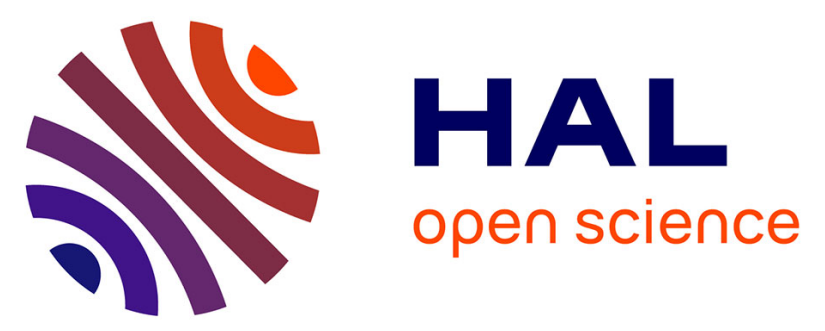

\title{
Unravelling the Beneficial Influence of Ag insertion on the Thermoelectric Properties of the Cluster Compound K2Mo15Se19
}

Gilles Daigre, Patrick Gougeon, Philippe Gall, Odile Merdrignac-Conanec, Rabih Al Rahal Al Orabi, Regis Gautier, Anne Dauscher, Christophe Candolfi, Bertrand Lenoir

\section{To cite this version:}

Gilles Daigre, Patrick Gougeon, Philippe Gall, Odile Merdrignac-Conanec, Rabih Al Rahal Al Orabi, et al.. Unravelling the Beneficial Influence of Ag insertion on the Thermoelectric Properties of the Cluster Compound K2Mo15Se19. ACS Applied Energy Materials, 2020, 3 (3), pp.2846-2855. 10.1021/acsaem.9b02488 . hal-02569139

\section{HAL Id: hal-02569139 https://hal.science/hal-02569139}

Submitted on 27 Nov 2020

HAL is a multi-disciplinary open access archive for the deposit and dissemination of scientific research documents, whether they are published or not. The documents may come from teaching and research institutions in France or abroad, or from public or private research centers.
L'archive ouverte pluridisciplinaire HAL, est destinée au dépôt et à la diffusion de documents scientifiques de niveau recherche, publiés ou non, émanant des établissements d'enseignement et de recherche français ou étrangers, des laboratoires publics ou privés. 


\title{
Unravelling the beneficial influence of Ag insertion on the thermoelectric properties of the cluster compound $\mathrm{K}_{2} \mathrm{Mo15}_{15} \mathrm{Se}_{19}$
}

Gilles Daigre $^{1}$, Patrick Gougeon ${ }^{1, *}$, Philippe Gall ${ }^{1}$, Odile Connanec-Merdrignac ${ }^{1}$, Rabih Al Rahal Al Orabi ${ }^{1}$, Régis Gautier ${ }^{1}$, Anne Dauscher ${ }^{2}$, Christophe Candolfi $^{2, *}$, Bertrand Lenoir ${ }^{2}$

${ }^{1}$ Univ Rennes, Ecole Nationale Supérieure de Chimie de Rennes, INSA Rennes, CNRS, ISCRUMR 6226, F-35000 Rennes, France

${ }^{2}$ Institut Jean Lamour, UMR 7198 CNRS - Université de Lorraine, Campus ARTEM, 2 allée André Guinier, BP 50840, 54011 Nancy, France

*Contact authors: patrick.gougeon@univ-rennes1.fr; christophe.candolfi@univ-lorraine.fr

\begin{abstract}
Mo-based cluster compounds are an emerging class of potential candidates for thermoelectric applications due to several key crystallographic characteristics that drive their ability to transport heat close to that of amorphous systems. Here, we report on a detailed investigation of the crystal structure and high-temperature transport properties of the cluster compound $\mathrm{K}_{2} \mathrm{Mo}_{15} \mathrm{Se}_{19}$ and of its $\mathrm{Ag}$-filled variant $\mathrm{Ag}_{3} \mathrm{~K}_{2} \mathrm{Mo}_{15} \mathrm{Se}_{19}$. Single-crystal X-ray diffraction confirm that both compounds crystallize with a hexagonal crystal structure, successfully solved in the space group $R \overline{3} c$, built by octahedral $\mathrm{Mo}_{6} \mathrm{Se} 8$ and bioctahedral Mo9Se $\mathrm{Se}_{11}$ clusters with $\mathrm{K}$ and Ag cations filling the large inter-cluster voids. In agreement with electronic band structure calculations, the electron transfer that occurs from the filling cations to the cluster subnetwork provides a simple guiding rule to predict the evolution of the transport properties upon filling
\end{abstract}


with Ag. The metallic state observed in $\mathrm{K}_{2} \mathrm{Mo}_{15} \mathrm{Se}_{19}$ is turned into a more heavily-doped semiconducting character in the presence of Ag resulting in enhanced thermopower values in $\mathrm{Ag}_{3} \mathrm{~K}_{2} \mathrm{Mo1}_{15} \mathrm{Se}_{19}$. The beneficial influence of $\mathrm{Ag}$ on the thermoelectric properties is also reflected by lowered lattice thermal conductivity values that reach $0.45 \mathrm{~W} \mathrm{~m}^{-1} \mathrm{~K}^{-1}$ at $750 \mathrm{~K}$. These results indicate that inserting an additional element in the ternaries $M_{2} \mathrm{Mo}_{15} \mathrm{Se}_{19}$ is an interesting route to improving their thermoelectric properties.

Keywords: Thermoelectric; molybdenum clusters; semiconductors; thermal conductivity; single crystal 


\section{INTRODUCTION}

In 1971, R. Chevrel, M. Sergent and J. Prigent discovered the "Chevrel phases" of generic chemical formula $M_{x} \mathrm{Mo}_{6} X_{8}(M=$ rare-earth, transition metals, $\mathrm{Na}, \mathrm{Ca}, \mathrm{Sr}, \mathrm{Ba}, \mathrm{Sn}, \mathrm{Pb} ; X=\mathrm{S}$, Se, Te), the crystal structure of which is built up by octahedral Mo6 clusters. ${ }^{1}$ These compounds exhibit many interesting physical properties such as high-field superconductivity in $\mathrm{PbMo6}_{8}$ or the coexistence of superconductivity and ferromagnetic order in $\mathrm{HoMo}_{6} \mathrm{Se} 8 .{ }^{2}$ The inherent metallic character of the electrical conduction in these compounds originates from the nature of the top of the valence bands, the presence of inter-cluster interactions and the flexibility of the electron count, that is, of the charge transfer between the Mo6 clusters and the $M$ cations.

Following these pioneering works, condensed molybdenum-based clusters Mo9 and Mo12 were obtained by increasing the metal-to-chalcogen ratio. ${ }^{3-5}$ The condensation process is realized by sharing Mo3 opposite triangular faces of the Mo6 octahedra whose ultimate stage leads to the uniaxial infinite chain of face-faced octahedra $\left|\mathrm{Mo}_{6 / 2}\right|_{\infty}$ observed in the quasi-1D $M_{2} \mathrm{Mo}_{6} X_{6}$ compounds $(M=\mathrm{Na}, \mathrm{Rb}, \mathrm{Cs}, \mathrm{Tl}$, In and $X=\mathrm{S}, \mathrm{Se}, \mathrm{Te}) .{ }^{6}$ Of note, the nearly $1 \mathrm{D}$ character of the crystal structure of these compounds gives rise to exotic superconductivity and possibly to novel types of fermionic excitations due to topologically non-trivial electronic band structures. ${ }^{7-10}$ So far, the intermediate Mo9, Mo12, Mo15, Mo18, Mo21, Mo24, Mo30 and Mo36 clusters have been observed in various compounds..$^{3-5,11-13}$

However, the thermoelectric properties of some of these ternary and quaternary molybdenum chalcogenides have only been assessed recently. ${ }^{14-23}$ Their inherent structural complexity, arising from a high number of atoms per unit cell and the presence of cations in the inter-cluster voids, is the key ingredient leading to very low lattice thermal conductivity $\kappa_{p h}$. Combined with electrical properties that can gradually evolve from metallic to semiconductinglike by inserting additional cations, this property can potentially yield high dimensionless 
thermoelectric figures of merit $Z T=\alpha^{2} T / \rho\left(\kappa_{e}+\kappa_{p h}\right)$ which determine the efficiency of a thermoelectric material at an absolute temperature $T .{ }^{14-23}$ The main challenge then lies in achieving concomitantly high thermopower $\alpha$, low electrical resistivity $\rho$, and low electronic thermal conductivity $\kappa_{e}$.

First studies performed on the Chevrel phases revealed their potential for hightemperature thermoelectric applications with a maximum $Z T$ of 0.6 at $1150 \mathrm{~K}$ for $\mathrm{Cu}_{2} \mathrm{FeMo} \mathrm{Me}_{8}$, rivaling those obtained in the state-of-the-art $\mathrm{Si}-\mathrm{Ge}$ solid solutions. ${ }^{24,25}$ Later on, initial investigations of the thermoelectric properties of the $\mathrm{Ag}_{x} \mathrm{Mog}_{9} \mathrm{Se}_{11}(3.4 \leq x \leq 3.8)$ compounds revealed equivalent $Z T$ values at $800 \mathrm{~K}$ ( $Z T$ of 0.65 for $x=3.8$ ) that notably arise from their very low lattice thermal conductivity approaching the amorphous limit at $800 \mathrm{~K}\left(0.5 \mathrm{~W} \mathrm{~m}^{-1} \mathrm{~K}^{-}\right.$ $\left.{ }^{1}\right) .{ }^{14,15,21}$ The physical origin of this glass-like thermal transport is related to the large voids separating the $\mathrm{Mog}_{9} \mathrm{Se}_{11}{ }_{11} \mathrm{Se}_{6}{ }_{6}$ bioctahedral clusters in which $\mathrm{Ag}^{+}$cations occupy four independent crystallographic sites and show large anisotropic thermal displacement parameters. The polymorph compounds $\mathrm{Ag}_{2} \mathrm{Tl}_{2} \mathrm{Mog}_{9} \mathrm{Se}_{11}$ and $\mathrm{Ag}_{3} \mathrm{RbMog}_{9} \mathrm{Se}_{11}$ that crystallize in the hexagonal space groups $R \overline{3} c$ and $P 6_{3} / m$, respectively, also combine very low $\kappa_{p h}$ values and semiconducting behavior yielding peak $Z T$ values of 0.6 and 0.4 at $800 \mathrm{~K}$, respectively. ${ }^{17,22}$

The $M_{2} \mathrm{Mo}_{15} \mathrm{Se}_{19}(M=\mathrm{K}, \mathrm{Ba}, \mathrm{In}, \mathrm{Tl}, \mathrm{Rb})$ compounds are another family investigated for their thermoelectric properties. ${ }^{16,19,23}$ Their crystal structure contains both $\mathrm{Mo}_{6} \mathrm{Se}_{8}{ }_{8} \mathrm{Se}_{6}{ }_{6}$ and

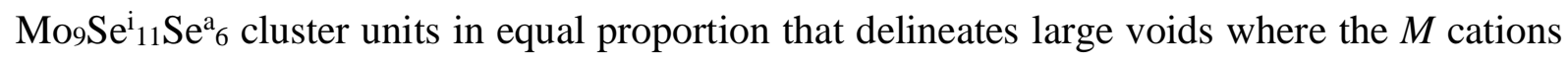
reside. In agreement with electronic band structure calculations, ${ }^{26}$ metallic electron counts (MEC) indicate that these materials are metallic, assuming a monovalent character of the $M$ cations. Driving these metallic properties towards semiconducting-like properties can be realized in filled variants by inserting additional cations such as Ag. This strategy has been successfully applied for $M=\mathrm{In}$ and Tl resulting in higher thermoelectric performances than in Ag-free compounds with peak $Z T$ values of 0.45 and 0.20 at 1100 and $800 \mathrm{~K}$, respectively. ${ }^{16,23}$ 
Following these encouraging results, we explore herein the transport properties of the isostructural compounds $\mathrm{K}_{2} \mathrm{Mo15}_{15} \mathrm{Se}_{19}$ and $\mathrm{Ag}_{3} \mathrm{~K}_{2} \mathrm{Mo}_{15} \mathrm{Se}_{19}$ to further elucidate the influence of the nature of the $M$ cations on the thermoelectric properties. The experimental results are compared with those reported on the In and $\mathrm{Tl}$ compounds outlined above and complemented by calculations of the electronic density of states.

\section{RESULTS AND DISCUSSION}

The two compounds $\mathrm{K}_{2} \mathrm{Mo}_{15} \mathrm{Se}_{19}$ and $\mathrm{Ag}_{3} \mathrm{~K}_{2} \mathrm{Moo}_{15} \mathrm{Se}_{19}$ are isostructural to $\mathrm{In}_{2} \mathrm{Mo}_{15} \mathrm{Se}_{19}$ and $\mathrm{Ag}_{3} \operatorname{In}_{2} \mathrm{Mo}_{15} \mathrm{Se}_{19}$, respectively, that both crystallize in the space group $R \overline{3} c$ (Tables 1 and 2 ). Their crystal structures are based on the two cluster units $\mathrm{Mo}_{6} \mathrm{Se}_{8} \mathrm{Se}_{6}$ and $\mathrm{Mo}_{9} \mathrm{Se}_{11} \mathrm{Se}_{6}$, the threedimensional arrangement of which is shown in Figure 1. These two units share ligands via the Mo1-Se2 and Se1-Mo2 bonds to ensure the three-dimensional cohesion of the crystal structure (Figure 2). Compared to the $\mathrm{K}_{2} \mathrm{Mo}_{15} \mathrm{Se}_{19}$ compound, the insertion of $\mathrm{Ag}$ atoms results in distorted Se sites forming trigonal bipyramids located between two consecutive $\mathrm{K}$ sites and in a modification of the $\mathrm{K}$ environment (Figures 3a and 3b). A clear shift of the $\mathrm{K}$ atoms towards the $\mathrm{Se} 5$ atoms is indeed observed with a significant decrease in the distance K-Se5 from 3.6760(15) $\AA$ in $\mathrm{K}_{2} \mathrm{Mo}_{15} \mathrm{Se}_{19}$ to 3.260(2) $\AA$ in $\mathrm{Ag}_{2.2} \mathrm{~K}_{2} \mathrm{Mo}_{15} \mathrm{Se}_{19}$. In contrast, the $\mathrm{Se} 3$ and $\mathrm{Se} 4$ atoms move away from K with K-Se3 and K-Se4 distances of 4.062(1) $\AA$ and 3.674(2) $\AA$ in

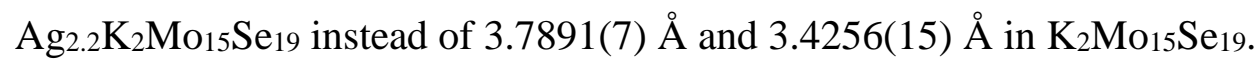

Ag insertion leads to variations in the Mo-Mo distances in both clusters due to the increase in the cationic charge transfer. In the Mo6 cluster (Table 3), a shortening of the inter-triangular

distance Mo1-Mo1 from 2.7675(3) $\AA$ in $\mathrm{K}_{2} \mathrm{Mo}_{15} \mathrm{Se}_{19}$ to $2.7146(4) \AA$ in $\mathrm{Ag}_{2.2} \mathrm{~K}_{2} \mathrm{Mo}_{15} \mathrm{Se}_{19}$ is observed upon increasing the cationic charge. In contrast, the intra-triangular Mo1-Mo1 distances remain practically unchanged. In the Mo9 cluster, in addition to the decrease in the 
inter-triangular Mo2-Mo3 distances (2.7138(2) Å to 2.6873(2) $\AA$ ), the intra-angular Mo3-Mo3 distance increases from 2.6821(3) $\AA$ in $\mathrm{K}_{2} \mathrm{Mo}_{15} \mathrm{Se}_{19}$ to $2.7158(5) \AA$ in $\mathrm{Ag}_{2.2} \mathrm{~K}_{2} \mathrm{Mo}_{15} \mathrm{Se}_{19}$. This modification is accompanied by a shortening of the intra-triangular Mo2-Mo2 distances from 2.6682(3) $\AA$ to 2.6424(4) $\AA$. All these variations in the interatomic distances are consistent with the theoretical calculations (see below) carried out on the host structure $\mathrm{K}_{2} \mathrm{Mo}_{15} \mathrm{Se}_{19}$.

The PXRD patterns of both polycrystalline specimens, shown in Figure 4, were successfully indexed by the structure model derived from single-crystal X-ray diffraction data. These data indicate the absence of secondary phases within experimental uncertainty. Rietveld refinements against the diffraction data for $\mathrm{Ag}_{3} \mathrm{~K}_{2} \mathrm{Mo}_{15} \mathrm{Se}_{19}$ showed that the occupancy factor of the Ag atom is 0.493(9), in very good agreement with the nominal chemical composition that corresponds to an occupancy factor of 0.5 . The crystallographic parameters determined from these refinements are given in Table S1 in Supporting Information. The atomic coordinates, equivalent isotropic displacement parameters and selected interatomic distances are listed in Table S2 and S3, respectively.

The good chemical homogeneity of the two samples is further confirmed by elemental Xray mapping (Figures S4 and S5 in Supporting Information) indicating that $\mathrm{Ag}$ and $\mathrm{K}$ are homogeneously distributed. In the $\mathrm{Ag}_{3} \mathrm{~K}_{2} \mathrm{Mo1}_{15} \mathrm{Se}_{19}$ compound, these experiments further indicate the presence of very small Ag-rich or K-rich areas, suggesting that local, weak compositional fluctuations in the $\mathrm{Ag} / \mathrm{K}$ ratio exist in this sample. The possibility that the overall cation content slightly varies spatially is in agreement with the single-crystal X-ray diffraction data evidencing an under-stoichiometric $\mathrm{Ag}$ concentration in the single-crystals studied. Nevertheless, as shown by these images, these Ag- or K-rich areas are very small and are thus not expected to significantly impact the measured transport properties. Fracture images collected on both samples evidence some differences in the microstructure of both samples (Figure S6 in Supporting Information). While the $\mathrm{Ag}_{3} \mathrm{~K}_{2} \mathrm{Mo}_{15} \mathrm{Se}_{19}$ compound is composed of 
micron-sized particles homogeneously distributed, the Ag-free compound is rather characterized by a coexistence of similar large grains with smaller ones, suggesting a broader size distribution than in $\mathrm{Ag}_{3} \mathrm{~K}_{2} \mathrm{Mo}_{15} \mathrm{Se}_{19}$. The corresponding elemental $\mathrm{X}$-ray mappings (Figures S7 and S8 in Supporting Information) show that this difference in the microstructure does not affect the homogeneous distribution of $\mathrm{Ag}$ and $\mathrm{K}$ in both polycrystalline samples.

The metallic electron count (MEC), that is, the number of electrons available for the formation of Mo-Mo bonds, optimizes metal-metal bonding in the Mo9Se 11 and $\mathrm{Mo}_{6} \mathrm{Se}_{8}$ clusters when equal to 36 and 24 , respectively. ${ }^{16}$ Assuming the absence of significant interaction between these clusters, the optimum MEC for the Mo15Se ${ }_{19}$ subnetwork is thus equal to 60 . The electronic DOS and COHP curves calculated for different Mo-Mo bonds confirm this analysis. The Fermi level is located almost at the top of the valence bands, predominantly centered on the Mo atoms. The small contribution of $\mathrm{K}$ states to the occupied bands confirms the ionic interaction with the transfer of $4 s$ electrons from $\mathrm{K}$ to the Mo15Se ${ }_{19}$ subnetwork (Figure 5). The COHP curves calculated for the Mo-Mo bonds in the Mo6 and Mo9 clusters show that the vacant bands at the top of the valence bands have mostly a weakly bonding or weakly anti-bonding character (Mo3-Mo3). Hence, these vacant bands can be considered as non-bonding as a first approximation. The COHP for the Mo1-Mo2 inter-cluster, shown in Figure 6, confirms the weak interaction between these patterns. A band gap of about $0.5 \mathrm{eV}$ separates the valence bands from the anti-wear strips. Within a rigid-band model (that is, independent of the electron count), an increase in the MEC up to 60 should therefore be possible without significantly altering the architecture of $\mathrm{K}_{2} \mathrm{Mo}_{15} \mathrm{Se}_{19}$.

For $\mathrm{Ag}_{3} \mathrm{~K}_{2} \mathrm{Mo15}_{15} \mathrm{Se}_{19}$, each inserted $\mathrm{Ag}$ atom transfers its valence electrons to the Mo-Se framework which increases the overall MEC of the $\mathrm{Mo}_{15} \mathrm{Se}_{19}$ clusters to 57 . The variations in the Mo-Mo distances observed in single-crystal X-ray diffraction data (Table 3) are in agreement with those expected in view of the COHP curves, considering the occupation of the 
bands located just above the Fermi level in $\mathrm{K}_{2} \mathrm{Mo}_{15} \mathrm{Se}_{19}$. Indeed, the observed shortening of the distances Mo1-Mo1, Mo2-Mo2 and Mo2-Mo3 is consistent with the Mo-Mo bonding character that binds bands above the Fermi level in $\mathrm{K}_{2} \mathrm{Mo}_{15} \mathrm{Se}_{19}$ (Figures 7 and 8). In contrast, the antibonding character of the Mo3-Mo3 and the intra-triangular Mo1-Mo1 bonds explains the observed increase in these distances upon inserting Ag.

According to the above-mentioned considerations of the MEC in these two compounds, the insertion of $\mathrm{Ag}$ into $\mathrm{K}_{2} \mathrm{Mo}_{15} \mathrm{Se}_{19}$ should drive this compound towards a more heavily-doped semiconducting state. This expectation should therefore be synonymous with an increase in the thermopower $\alpha$ in $\mathrm{Ag}_{3} \mathrm{~K}_{2} \mathrm{Mo}_{15} \mathrm{Se}_{19}$ with respect to $\mathrm{K}_{2} \mathrm{Mo}_{15} \mathrm{Se}_{19}$. A comparison of the temperature dependences of $\alpha$, shown in Figure 9a, confirms this simple picture with a significant increase in the $\alpha$ values in $\mathrm{Ag}_{3} \mathrm{~K}_{2} \mathrm{Mo}_{15} \mathrm{Se}_{19}$ over the entire temperature range. However, a concomitant increase in $\rho$ that may be expected due to a decrease in the carrier concentration is not observed (Figure $9 \mathrm{~b}$ ). In contrast, $\mathrm{Ag}_{3} \mathrm{~K}_{2} \mathrm{Mo}_{15} \mathrm{Se}_{19}$ shows lower $\rho$ values compared to $\mathrm{K}_{2} \mathrm{Mo}_{15} \mathrm{Se}_{19}$, resulting in higher power factor compared to the Ag-free compound (Figure S9 in supporting Information). This trend is not due to differences in the relative density of the two polycrystalline samples since both consolidated pellets exhibit similar geometric densities. This difference may be related to the different microstructures of the two samples evidenced by fracture images. The broader distribution of grain size suggested by these images in $\mathrm{K}_{2} \mathrm{Mo}_{15} \mathrm{Se}_{19}$ may result in lower carrier mobilities resulting in increased $\rho$ values. Alternatively to microstructure effects, a decrease in the electron-phonon coupling strength induced by the addition of $\mathrm{Ag}$ could also explain higher hole mobilities in $\mathrm{Ag}_{3} \mathrm{~K}_{2} \mathrm{Mo}_{15} \mathrm{Se}_{19}$ compared to $\mathrm{K}_{2} \mathrm{Mo}_{15} \mathrm{Se}_{19}$, as suggested recently in the $\mathrm{Cs}_{2} \mathrm{Mo}_{12} \mathrm{Se}_{14}$ cluster compound upon $\mathrm{Cu}$ insertion. ${ }^{18}$ A detailed analysis of this possibility based on Hall effect measurements is however complicated in the present compounds due to the high hole concentrations giving rise to small Hall signals difficult to resolve experimentally, should it be measured at low or high 
temperatures. Indeed, as documented for several other Mo-based cluster compounds, the Hall signal is often composed of electron-like and hole-like contributions which tend to cancel out. ${ }^{14-}$ 23

The total thermal conductivity $\kappa$, shown in Figure $9 \mathrm{c}$, exhibits a similar linear temperature dependence in both compounds, varying upon warming from 1.0 and $1.2 \mathrm{~W} \mathrm{~m}^{-1} \mathrm{~K}^{-1}$ at $300 \mathrm{~K}$ to 1.6 and $2.0 \mathrm{~W} \mathrm{~m}^{-1} \mathrm{~K}^{-1}$ at $800 \mathrm{~K}$ in the $\mathrm{Ag}_{3} \mathrm{~K}_{2} \mathrm{Mo}_{15} \mathrm{Se}_{19}$ and $\mathrm{K}_{2} \mathrm{Mo}_{15} \mathrm{Se}_{19}$ compounds, respectively. The electronic thermal conductivity $\kappa_{e}$ has been estimated using the WiedemannFranz law $\kappa_{e}=L T / \rho$ where $L$ is the Lorenz number (Figure S10 in Supporting Information). In order to take into account possible variations in $L$ in this temperature range, the temperature dependence of $L$ has been calculated assuming a single-parabolic band model with acoustic phonon scattering. The subtraction of $\kappa_{e}$ from $\kappa$ leaves the lattice contribution $\kappa_{p h}$, shown in Figure 9c as a function of temperature for both compounds. The insertion of $\mathrm{Ag}$ leads to a substantial reduction in the heat transport from $1.05 \mathrm{~W} \mathrm{~m}^{-1} \mathrm{~K}^{-1}$ in $\mathrm{K}_{2} \mathrm{Mo}_{15} \mathrm{Se}_{19}$ to $0.45 \mathrm{~W} \mathrm{~m}^{-1} \mathrm{~K}^{-}$ ${ }^{1}$ in $\mathrm{Ag}_{3} \mathrm{~K}_{2} \mathrm{Mo}_{15} \mathrm{Se}_{19}$ at $800 \mathrm{~K}$. This strong decrease in $\kappa_{p h}$ is a result of an increased complexity in the unit cell and of the probable presence of additional low-energy optical modes related to the large thermal motion of the Ag atoms. The addition of Ag helps to bring the heat transport down to its theoretical minimum estimated by the model developed by Cahill and Pohl where the high-temperature limit of the minimum thermal conductivity $\kappa_{\min }$ is expressed as ${ }^{27}$

$$
\kappa_{\min }=\frac{1}{2}\left(\frac{\pi}{6}\right)^{1 / 3} k_{B} V^{-2 / 3}\left(2 v_{T}+v_{L}\right)
$$

In this expression, $k_{B}$ is the Boltzmann constant, $V$ is the atomic volume and $v_{T}$ and $v_{L}$ are the transverse and longitudinal sound velocities. In the present case, room-temperature measurements of $v_{T}$ and $v_{L}$ by a pulse-echo method yields $\kappa_{\min } \approx 0.45 \mathrm{~W} \mathrm{~m}^{-1} \mathrm{~K}^{-1}$ for both compounds.

The temperature dependence of the dimensionless thermoelectric figure of merit $Z T$, shown in Figure 9d, evidences the overall beneficial influence of Ag on the thermoelectric 
properties of $\mathrm{K}_{2} \mathrm{Mo}_{15} \mathrm{Se}_{19}$. The concomitant increase in the power factor $\alpha^{2} / \rho$ and decrease in $\kappa_{p h}$ driven by the insertion of $\mathrm{Ag}$ results in a nearly eightfold increase in the $Z T$ values with a peak value of 0.18 at $800 \mathrm{~K}$. This maximum value is similar to that achieved in the Tl-containing analogue $(0.19$ at $800 \mathrm{~K})$ but lower than that obtained in the In-containing compound $(0.26$ at $800 \mathrm{~K}) \cdot{ }^{16,23}$

Although all these compounds seem similar according to their respective MEC, these results show that the nature of the transport properties are sensitive to the nature of the $M$ cation. The fact that these different elements are not electronically equivalent in these compounds may have several origins. First, the MEC count relies on the assumption that the $M$ cations exhibit a +1 valence state. In the $\mathrm{Ag}_{x} \mathrm{Mog}_{9} \mathrm{Se}_{11}$ compounds, combined high-resolution fluorescencedetection X-ray absorption spectroscopy (HERFD-XAS) and resonant inelastic X-ray scattering (RIXS) measurements have evidenced the presence of sub-monovalent $\mathrm{Ag}$ atoms. ${ }^{28} \mathrm{The}$ presence of a similar property in the $\mathrm{Ag}_{3} M_{2} \mathrm{Mo}_{15} \mathrm{Se}_{19}$ compounds would explain the differences observed in their transport properties. In addition, the actual charge of the $\mathrm{Ag}$ and $M$ atoms in these structures may likely vary depending on the nature and atomic size of the $M$ cations and on the actual concentrations of both $\mathrm{Ag}$ and $M$. Alternatively, these differences may be due to slight but systematic variations in the valence bands as a function of the $M$ cations. In particular, these modifications might change the balance between the electron- and hole-like contributions usually observed in the Hall signal which, in turn, would alter their impact on the thermopower values and hence, on the $Z T$ values. Because both mechanisms could be at play in these compounds, further experimental investigations with HERFD-XAS and RIXS would be valuable to systematically probe the valence state of the $\mathrm{Ag}$ and $M$ cations. 


\section{CONCLUSION}

The novel reduced molybdenum selenides $\mathrm{K}_{2} \mathrm{Mo}_{15} \mathrm{Se}_{19}$ and $\mathrm{Ag}_{3} \mathrm{~K}_{2} \mathrm{Mo}_{15} \mathrm{Se}_{19}$ were synthesized by solid-state reaction at $1300^{\circ} \mathrm{C}$ in sealed Mo crucibles. As in $\operatorname{In}_{2} \mathrm{Mo}_{15} \mathrm{Se}_{19}$, the crystal structure contains an equal proportion of octahedral Mo6 and bioctahedral Mo9 clusters, forming $\mathrm{Mo}_{6} \mathrm{Se}^{\mathrm{i}}{ }_{8} \mathrm{Se}^{\mathrm{a}} 6$ and $\mathrm{Mo}_{9} \mathrm{Se}^{\mathrm{i}}{ }_{11} \mathrm{Se}^{\mathrm{a}} 6$ cluster units, separated from each other by large voids. These voids are filled up by eleven-coordinated $\mathrm{K}$ atoms in $\mathrm{K}_{2} \mathrm{Mo}_{15} \mathrm{Se}_{19}$ and by five-coordinated $\mathrm{Ag}$ atoms in $\mathrm{Ag}_{3} \mathrm{~K}_{2} \mathrm{Mo}_{15} \mathrm{Se}_{19}$. In agreement with simple metallic electron count and electronic band structure calculations, $\mathrm{K}_{2} \mathrm{Mo}_{15} \mathrm{Se}_{19}$ is a $p$-type metal with moderate thermopower values. Upon inserting Ag, a clear evolution of these properties towards a heavily-doped semiconducting state is observed. In addition to influencing the electronic properties, the presence of Ag further lowers the phonon transport close to the amorphous limit. Very low-temperature thermodynamic measurements and spectroscopic probes will be of interest to establish in detail the microscopic origin of this behavior. The comparison of the transport properties measured herein with those reported for the In and Tl-containing analogues suggests that the nature of $M$ cation is an important parameter to tune the thermoelectric performances. Future investigations of the transport properties of these compounds with other $M$ atoms will be helpful to better understand its role and to develop structure-properties relationships in this family of cluster compounds.

\section{Supporting Information.}

Experimental and computational details, details of the crystallographic data collection and powder X-ray structural analysis, final atomic coordinates and equivalent isotropic displacement parameters, selected interatomic distances for polycrystalline $\mathrm{Ag}_{3} \mathrm{~K}_{2} \mathrm{Mo}_{15} \mathrm{Se}_{19}$ determined from profile matching against the PXRD data, temperature dependence of the 
thermal diffusivity for both samples, temperature dependence of the thermal conductivity $\kappa$ measured perpendicular (low temperature) and parallel (high temperature) to the pressing direction for $\mathrm{K}_{2} \mathrm{Mo}_{15} \mathrm{Se}_{19}$ and $\mathrm{Ag}_{3} \mathrm{~K}_{2} \mathrm{Mo}_{15} \mathrm{Se}_{19}$, temperature dependence of the specific heat $C_{p}$ for $\mathrm{K}_{2} \mathrm{Mo}_{15} \mathrm{Se}_{19}$ and $\mathrm{Ag}_{3} \mathrm{~K}_{2} \mathrm{Mo}_{15} \mathrm{Se}_{19}$, elemental $\mathrm{X}$-ray mapping for $\mathrm{K}_{2} \mathrm{Mo}_{15} \mathrm{Se}_{19}$ and $\mathrm{Ag}_{3} \mathrm{~K}_{2} \mathrm{Mo1}_{15} \mathrm{Se}_{19}$, fracture images for $\mathrm{K}_{2} \mathrm{Mo}_{15} \mathrm{Se}_{19}$ and $\mathrm{Ag}_{3} \mathrm{~K}_{2} \mathrm{Mo15}_{15} \mathrm{Se}_{19}$, elemental fracture images and their corresponding elemental X-ray mapping for $\mathrm{K}_{2} \mathrm{Mo}_{15} \mathrm{Se}_{19}$ and $\mathrm{Ag}_{3} \mathrm{~K}_{2} \mathrm{Mo}_{15} \mathrm{Se}_{19}$, temperature dependence of the power factor, temperature dependence of the electronic thermal conductivity.

\section{AUTHOR INFORMATION}

\section{Corresponding Authors}

*christophe.candolfi@univ-lorraine.fr

*patrick.gougeon@univ-rennes1.fr

\section{ORCID}

Christophe Candolfi: 0000-0002-1248-5354

Patrick Gougeon: 0000-0003-4778-5581

Rabih Al Rahal Al Orabi: 0000-0001-5880-5838

Anne Dauscher: 0000-0002-5857-3421

Bertrand Lenoir: 0000-0001-9631-4925

\section{Notes}

The authors declare no competing financial interest.

\section{Conflicts of interest}

There are no conflicts to declare. 


\section{REFERENCES}

(1) Chevrel, R.; Sergent, M.; Prigent, J. Sur de nouvelles phases sulfurées ternaires du molybdène. J. Solid State Chem. 1971, 3, 515-519.

(2) Fischer, Ø. Chevrel Phases: Superconducting and Normal State Properties. Appl. Phys. 1978, 16, 1-28.

(3) Gougeon, P.; Padiou, J.; Le Marouille, J.-Y.; Potel, M.; Sergent, M. Ag3.6Mo9Se 11 Premier Composé à Clusters Mo9 dans des Motifs Mo9Se11. J. Solid State Chem. 1984, 51, 218-226.

(4) Gougeon, P.; Potel, M.; Padiou, J.; Sergent, M. Synthesis, Crystal Structure and Electrical Properties of the First Compound Containing Uniquely Mo12Se ${ }_{14}$ Cluster Units. Mater. Res. Bull. 1987, 22, 1087-1092.

(5) Gautier, R.; Picard, S.; Gougeon, P.; Potel, M. Synthesis, Crystal and Electronic Structures, and Electrical Properties of $\mathrm{Rb}_{2} \mathrm{Mo}_{12} \mathrm{Se}_{14}$ Containing Trioctahedral Mo12 Clusters. Mater. Res. Bull. 1999, 34, 93-101.

(6) Tarascon, J. M.; DiSalvo, F. J.; Waszczak, J. V. Physical properties of several $M_{2} \mathrm{Mo}_{6} \mathrm{X}_{6}$ compounds $(M=$ GROUP IA METAL; $X=$ Se, Te). Solid State Commun. 1984, 52, 227-331. (7) Petrovic, A. P.; Ansermet, D.; Chernyshov, D.; Hoesch, M.; Salloum, D.; Gougeon, P.; Potel, M.; Boeri, L.; Panagopoulos, C. A disorder-enhanced quasi-one-dimensional superconductor. Nat. Commun. 2016, 7, 12262.

(8) Gannon, L.; Boeri, L.; Howard, C. A.; Gougeon, P.; Gall, P.; Potel, M.; Salloum, D.; Petrovic, A. P.; Hoesch, M. Lattice dynamics of the cluster chain compounds $M_{2} \mathrm{Mo6}_{6} \mathrm{Se}_{6}(M=$ K, Rb, Cs, In, and Tl) Phys. Rev. B 2018, 98, 014104.

(9) Mitra, S.; Petrovic, A. P.; Salloum, D.; Gougeon, P.; Potel, M.; Zhu, J.-X.; Panagopoulos, C.; Chia, E. E. M. Dimensional crossover in the quasi-one-dimensional superconductor Tl2 Mo6Se6. Phys. Rev. B 2018, 98, 054507. 
(10) Liu, Q.; Zunger, A. Predicted Realization of Cubic Dirac Fermion in Quasi-OneDimensional Transition-Metal Monochalcogenides. Phys. Rev. X 2017, 7, 021019.

(11) Gougeon, P.; Potel, M.; Sergent, M. Structure of Rb33015Se 17 Containing the New Mo15 Clusters. Acta Crystallogr. 1989, C45, 182-185.

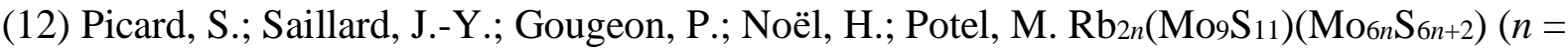
1 to 4): A Novel Family of Superconducting Molybdenum Cluster Compounds. J. Solid State Chem. 2000, 155, 417-426.

(13) Picard, S.; Gougeon, P.; Potel, M. Single-Crystal Structure of Cs5Mo21S 23 . Acta Crystallogr. 1997, C53, 1519-1521.

(14) Zhou, T.; Lenoir, B.; Colin, M.; Dauscher, A.; Al Rahal Al Orabi, R.; Gougeon, P.; Potel, M.; Guilmeau, E. Promising Thermoelectric Properties in $\mathrm{Ag}_{x} \mathrm{Mog}_{9} \mathrm{Se}_{11}$ Compounds $(3.4 \leq x \leq$ 3.9). Appl. Phys. Lett. 2011, 98, 162106.

(15) Zhou, T.; Colin, M.; Candolfi, C.; Boulanger, C.; Dauscher, A.; Santava, E.; Hejtmanek, J.; Baranek, P.; Al Rahal Al Orabi, R.; Potel, M.; Fontaine, B.; Gougeon, P.; Gautier, R.; Lenoir, B. Comprehensive Study of the Low-Temperature Transport and Thermodynamic Properties of the Cluster Compounds $\mathrm{Ag}_{x} \mathrm{Mog}_{\mathrm{Se}}{ }_{11}(3.41 \leq x \leq 3.78)$. Chem. Mater. 2014, 26, 4765-4775.

(16) Gougeon, P.; Gall, P.; Al Rahal Al Orabi, R.; Fontaine, B.; Gautier, R.; Potel, M.; Zhou, T.; Lenoir, B.; Colin, M.; Candolfi, C.; Dauscher, A. Synthesis, Crystal and Electronic Structures, and Thermoelectric Properties of the Novel Cluster Compound $\mathrm{Ag}_{3} \operatorname{In}_{2} \mathrm{Mo}_{15} \mathrm{Se}_{19}$. Chem. Mater. 2012, 24, 2899-2908.

(17) Al Rahal Al Orabi, R.; Gougeon, P.; Gall, P.; Fontaine, B.; Gautier, R.; Colin, M.; Candolfi, C.; Dauscher, A.; Hejtmanek, J.; Malaman, B.; Lenoir, B. X-ray Characterization, Electronic Band Structure, and Thermoelectric Properties of the Cluster Compound $\mathrm{Ag}_{2} \mathrm{Tl}_{2} \mathrm{Mog}_{9} \mathrm{Se}_{11}$. Inorg. Chem. 2014, 53, 11699-11709. 
(18) Al Rahal Al Orabi, R.; Fontaine, B.; Gautier, R.; Gougeon, P.; Gall, P.; Bouyrie, Y.; Dauscher, A.; Candolfi, C.; Lenoir, B. Cu Insertion Into the Mo12 Cluster Compound $\mathrm{Cs}_{2} \mathrm{Mo}_{12} \mathrm{Se}_{14}$ : Synthesis, Crystal and Electronic Structures, and Physical Properties. Inorg. Chem. 2016, 55, 6616-6624.

(19) Daigre, G.; Gougeon, P.; Gall, P.; Gautier, R.; Guillou, O.; Vaney, J.-B.; Candolfi, C.; Dauscher, A.; Lenoir, B. Synthesis, Crystal Structure and High-Temperature Transport Properties of the New Cluster Compound $\mathrm{Rb}_{2} \mathrm{Mo}_{15} \mathrm{Se}_{19}$. J. Solid State Chem. 2016, 237, 1-6.

(20) Masschelein, P.; Candolfi, C.; Dauscher, A.; Gendarme, C.; Al Rahal Al Orabi, R.; Gougeon, P.; Potel, M.; Gall, P.; Gautier, R.; Lenoir, B. Influence of S and Te substitutions on the thermoelectric properties of the cluster compound $\mathrm{Ag}_{3.8} \mathrm{Mog}_{9} \mathrm{Se}_{11}$. J. Alloys Compd. 2018, $739,360-367$.

(21) Colin, M.; Zhou, T.; Lenoir, B.; Dauscher, A.; Al Rahal Al Orabi, R.; Gougeon, P.; Potel, M.; Baranek, P.; Semprimoschnig, C. Optimization of Bulk Thermoelectrics: Influence of Cu Insertion in $\mathrm{Ag}_{3.6} \mathrm{Mog}_{9} \mathrm{Se}_{11}$. J. Electron. Mater. 2012, 41, 1360-1364.

(22) Gougeon, P.; Gall, P.; Merdrignac-Conanec, O.; Aranda, L.; Dauscher, A.; Candolfi, C.; Lenoir, B. Synthesis, Crystal Structure, and Transport Properties of the Hexagonal Mog Cluster Compound Ag3 RbMo9Se11. Inorg. Chem. 2017, 56, 9684-9692.

(23) Gougeon, P.; Gall, P.; Al Rahal Al Orabi, R.; Boucher, B.; Fontaine, B.; Dauscher, A.; Candolfi, C.; Lenoir, B. Electronic Band Structure and Transport Properties of the Cluster Compound $\mathrm{Ag}_{3} \mathrm{Tl}_{2} \mathrm{Mo1}_{15} \mathrm{Se}_{19}$. Inorg. Chem. 2019, 58, 5533-5542.

(24) Caillat, T.; Fleurial, J.-P.; Snyder, G. J. Potential of Chevrel phases for thermoelectric applications. Solid State Sci. 1999, 1, 535-544.

(25) Thermoelectrics and Its Energy Harvesting; Rowe, D. M., Ed.; CRC Press: Boca Raton, FL, 2012.

(26) Al Rahal Al Orabi, R.; Boucher, B.; Fontaine, B.; Gall, P.; Candolfi, C.; Lenoir, B.; 
Gougeon, P.; Halet, J.-F.; Gautier, R. Towards the prediction of the transport properties of cluster-based molybdenum chalcogenides. J. Mater. Chem. C 2017, 5, 12097-12104.

(27) Cahill, D. G.; Watson, S. K.; Pohl, R. O. Lower limit to the thermal conductivity of disordered crystals. Phys. Rev. B 1992, 46, 6131-6140.

(28) Butorin, S. M.; Kvashnina, K. O.; Klintenberg, M.; Kavcic, M.; Zitnik, M.; Bucar, K.; Gougeon, P.; Gall, P.; Candolfi, C.; Lenoir, B. Effect of Ag Doping on Electronic Structure of Cluster Compounds $\mathrm{Ag}_{x} \mathrm{Mog}_{9} \mathrm{Se}_{11}(x=3.4,3.9)$. ACS Appl. Energy Mater. 2018, 1, 4032-4039. 


\section{Tables}

Table 1. Single-crystal data collection and structure refinements of $\mathrm{K}_{2} \mathrm{Mo}_{15} \mathrm{Se}_{19}$ and $\mathrm{Ag}_{2.2} \mathrm{~K}_{2} \mathrm{Mo}_{15} \mathrm{Se}_{19}$ at $300 \mathrm{~K}$.

\begin{tabular}{|c|c|c|}
\hline Empirical chemical formula & $\mathrm{K}_{2} \mathrm{Mo}_{15} \mathrm{Se}_{19}$ & $\mathrm{Ag}_{2.2} \mathrm{~K}_{2} \mathrm{Mo}_{15} \mathrm{Se}_{19}$ \\
\hline Molar mass $\left(\mathrm{g} \cdot \mathrm{mol}^{-1}\right)$ & 3017.54 & 3251.76 \\
\hline Symmetry & \multicolumn{2}{|c|}{ Trigonal } \\
\hline Space group & \multicolumn{2}{|c|}{$R \overline{3} c$} \\
\hline$a(\AA)$ & $9.7229(10)$ & $9.96150(10)$ \\
\hline$c(\AA)$ & $58.2467(8)$ & $57.5198(9)$ \\
\hline $\mathrm{V}\left(\AA^{3}\right)$ & $4768.63(10)$ & $4943.08(10)$ \\
\hline$Z$ & \multicolumn{2}{|r|}{6} \\
\hline$d\left(\mathrm{~g} \cdot \mathrm{cm}^{-3}\right)$ & 6.305 & 6.558 \\
\hline Crystal color and habit & black, irregular & black, irregular \\
\hline Crystal size $\left(\mathrm{mm}^{3}\right)$ & $0.142 \times 0.094 \times 0.071$ & $0.205 \times 0.117 \times 0.108$ \\
\hline Radiation & Mo K $\alpha$ & Mo K $\alpha$ \\
\hline$\theta$ range $\left(^{\circ}\right)$ & $3.70-44.56$ & $3.69-39.996$ \\
\hline Absorption coefficient $\left(\mathrm{mm}^{-1}\right)$ & 27.705 & 27.992 \\
\hline Limiting indices & $-19 \leq h \leq 17,-18 \leq k \leq 19,-114 \leq l \leq 95$ & $-18 \leq h \leq 17,-18 \leq k \leq 16,-103 \leq l \leq 103$ \\
\hline Reflections collected/unique & $57775 / 4288$ & $45416 / 3410$ \\
\hline$R$ (int) & 0.0776 & 0.0807 \\
\hline Absorption correction & analytical & analytical \\
\hline Max./min. transmission & $0.2811 / 0.1219$ & $0.1689 / 0.0376$ \\
\hline Data/restraints/parameters & $4288 / 0 / 57$ & $3410 / 0 / 67$ \\
\hline$R$ indices $[I>2 \sigma(I)]$ & $\mathrm{R} 1=0.0310, w \mathrm{R} 2=0.0520$ & $\mathrm{R} 1=0.0296, w \mathrm{R} 2=0.0485$ \\
\hline Extinction coefficient & $0.000053(3)$ & $0.000138(4)$ \\
\hline Largest diff. peak and hole $\left(\mathrm{e}^{-3}\right)$ & 1.795 and -2.192 & 2.584 and -2.170 \\
\hline Goodness-of-fit on $F^{2}$ & 1.058 & 1.140 \\
\hline
\end{tabular}


Table 2. Fractional atomic coordinates, equivalent isotropic thermal displacement parameters (in $\AA^{2}$ ) and site occupancy factors for single-crystalline $\mathrm{K}_{2} \mathrm{Mo}_{15} \mathrm{Se}_{19}$ and $\mathrm{Ag}_{2.2} \mathrm{~K}_{2} \mathrm{Mo}_{15} \mathrm{Se}_{19}$.

\begin{tabular}{|l|l|l|l|l|l|}
\hline \multicolumn{1}{|c|}{ Atom } & \multicolumn{1}{|c|}{$x$} & \multicolumn{1}{c|}{$y$} & \multicolumn{1}{c|}{$z$} & \multicolumn{1}{c|}{$U_{\mathrm{eq}}$} & s.o.f \\
\hline Mo1 & $0.64652(2)$ & $-0.51856(2)$ & $0.35303(2)$ & $0.00774(4)$ & 1 \\
\hline Mo2 & $0.84743(2)$ & $-0.16372(2)$ & $0.28925(2)$ & $0.00774(4)$ & 1 \\
\hline Mo3 & $0.84074(3)$ & 0.0000 & 0.2500 & $0.00727(5)$ & 1 \\
\hline Se1 & $0.62840(3)$ & $-0.37968(3)$ & $0.31684(2)$ & $0.00935(4)$ & 1 \\
\hline Se2 & $0.65235(3)$ & $-0.30839(3)$ & $0.38094(2)$ & $0.01032(5)$ & 1 \\
\hline Se3 & $0.69207(3)$ & $-0.30793(3)$ & 0.2500 & $0.01105(6)$ & 1 \\
\hline Se4 & 0.6667 & -0.6667 & $0.38756(2)$ & $0.01267(8)$ & 1 \\
\hline Se5 & 1.0000 & 0.0000 & $0.32386(2)$ & $0.01081(7)$ & 1 \\
\hline K & 1.0000 & 0.0000 & $0.38697(2)$ & $0.0314(3)$ & 1 \\
\hline
\end{tabular}

\begin{tabular}{|l|l|l|l|l|l|}
\hline \multicolumn{1}{|c|}{ Atom } & \multicolumn{1}{|c|}{$x$} & \multicolumn{1}{|c|}{$y$} & \multicolumn{1}{c|}{$z$} & \multicolumn{1}{c|}{$U_{\text {eq }}$} & s.o.f \\
\hline Mo1 & $0.65070(3)$ & $-0.51996(3)$ & $0.35272(2)$ & $0.00546(4)$ & 1 \\
\hline Mo2 & $0.85270(3)$ & $-0.15840(3)$ & $0.28920(2)$ & $0.00581(5)$ & 1 \\
\hline Mo3 & $0.84259(3)$ & 0.0000 & 0.2500 & $0.00480(5)$ & 1 \\
\hline Se1 & $0.63359(3)$ & $-0.38357(3)$ & $0.31594(2)$ & $0.00793(6)$ & 1 \\
\hline Se2 & $0.64789(3)$ & $-0.30520(4)$ & $0.37892(2)$ & $0.00943(6)$ & 1 \\
\hline Se3 & $0.70133(4)$ & $-0.29867(4)$ & 0.2500 & $0.00858(7)$ & 1 \\
\hline Se4 & 0.6667 & -0.6667 & $0.38847(2)$ & $0.01002(9)$ & 1 \\
\hline Se5 & 1.0000 & 0.0000 & $0.32432(2)$ & $0.01029(9)$ & 1 \\
\hline K & 1.0000 & 0.0000 & $0.38101(4)$ & $0.0400(4)$ & 1 \\
\hline Ag & $0.70336(14)$ & $0.79923(10)$ & $0.08127(3)$ & $0.0314(4)$ & $0.3697(12)$ \\
\hline
\end{tabular}


Table 3. Selected interatomic distances (in $\AA$ ) for single-crystalline $\mathrm{K}_{2} \mathrm{Mo}_{15} \mathrm{Se}_{19}$ and $\mathrm{Ag}_{2.2} \mathrm{~K}_{2} \mathrm{Mo}_{15} \mathrm{Se}_{19}$.

$\mathrm{K}_{2} \mathrm{Mo}_{15} \mathrm{Se}_{19}$

$\underline{\mathrm{Mo6} \mathrm{Se}_{8} \text { unit }}$

Mo1-Mo1 (×2) intratriangle

Mo1-Mo1 (×2) intertriangle

Mo1-Se4

Mo1-Se2

Mo1-Se1

Mo1-Se1

$\underline{\text { MogSe}} 11$ unit

Mo2-Mo2 (×2) intratriangle

Mo3-Mo3 (×2) intratriangle

Mo2-Mo3 intertriangle

Mo1-Mo2 intercluster

Mo2-Se5

$\mathrm{Mo} 2-\mathrm{Se} 2$

Mo2-Se2

Mo2-Se1

Mo2-Se3

Mo3-Se2

Mo3-Se3

$\mathrm{K}-\mathrm{Se} 1$

$\mathrm{K}-\mathrm{Se} 2$

$\mathrm{K}-\mathrm{Se} 3$

$\mathrm{K}-\mathrm{Se} 4$

$\mathrm{K}-\mathrm{Se} 5$

Ag-Se2

Ag-Se2

$\mathrm{Ag}-\mathrm{Se} 3$

Ag-Se4
2.6799(3)

$2.7675(3)$

2.5374(4)

2.5898(3)

2.5968(3)

2.6092(4)

2.6682(3)

2.6821(3)

$2.7138(2)$

$3.459(2)$

$2.5370(4)$

$2.5818(3)$

2.6105(3)

2.6563(3)

2.7123(3)

2.5345(3)

2.5933(3)

$3.7959(8)$

$3.2255(3)$

3.7891(7)

$3.4256(15)$

$3.6760(15)$
$\mathrm{Ag}_{2.2} \mathrm{~K}_{2} \mathrm{Mo}_{15} \mathrm{Se}_{19}$

2.6797(4)

2.7146(4)

2.5733(4)

2.6282(4)

2.5902(4)

2.6030(3)

2.6424(4)

2.7158(5)

2.6873(2)

$3.579(3)$

2.5317(4)

2.5747(4)

2.6300(4)

2.6957(4)

2.6837(3)

2.6086(3)

2.5779(3)

$3.7050(10)$

3.3010(3)

4.0618(11)

3.673(2)

$3.260(2)$

2.5829(14)

2.7194(13)

2.5505(8)

$3.0135(10)$ 


\section{Figure Captions}

Figure 1. Views of the crystal structures of (a) $\mathrm{K}_{2} \mathrm{Mo}_{15} \mathrm{Se}_{19}$ and (b) $\mathrm{Ag}_{2.2} \mathrm{~K}_{2} \mathrm{Mo}_{15} \mathrm{Se}_{19}$ projected along the [010] direction. Thermal displacement ellipsoids were drawn at the $97 \%$ probability level.

Figure 2. Inter-unit linkage of the $\mathrm{Mog}_{9} \mathrm{Se}_{11} \mathrm{Se}_{6}$ and $\mathrm{Mo}_{6} \mathrm{Se}_{8} \mathrm{Se}_{6}$ cluster units. Thermal displacement ellipsoids were drawn at the $97 \%$ probability level.

Figure 3. a) Se environment of the $\mathrm{K}^{+}$cations in $\mathrm{K}_{2} \mathrm{Mo}_{15} \mathrm{Se}_{19}$. b) Se environment of the $\mathrm{Ag}^{+}$ and $\mathrm{K}^{+}$cations in $\mathrm{Ag}_{2.2} \mathrm{~K}_{2} \mathrm{Mo}_{15} \mathrm{Se}_{19}$.

Figure 4. Profile matching refinement of the powder X-ray diffraction patterns of $\mathrm{K}_{2} \mathrm{Mo}_{15} \mathrm{Se}_{19}$ (top) and $\mathrm{Ag}_{3} \mathrm{~K}_{2} \mathrm{Mo}_{15} \mathrm{Se}_{19}$ (bottom) $(\lambda=1.5406 \AA$ ). The black circles, red line and bottom black line correspond to the experimental, calculated and difference profile, respectively. All the observed reflections are consistent with the crystal structure determined from refinements against the single-crystal X-ray diffraction data. The vertical ticks mark the calculated positions of the reflections.

Figure 5. Total and partial densities of states as a function of the energy in $\mathrm{K}_{2} \mathrm{Mo}_{15} \mathrm{Se}_{19}$.

Figure 6. COHP curves calculated for the Mo-Mo intra-bonds in the Mo6 cluster for $\mathrm{K}_{2} \mathrm{Mo}_{15} \mathrm{Se}_{19}$. 
Figure 7. COHP curves calculated for the Mo-Mo intra-bonds in the Mog cluster for $\mathrm{K}_{2} \mathrm{Mo}_{15} \mathrm{Se}_{19}$.

Figure 8. COHP curves calculated for the inter-cluster bonds Mo1-Mo2 for $\mathrm{K}_{2} \mathrm{Mo}_{15} \mathrm{Se}_{19}$.

Figure 9. Temperature dependence of the a) electrical resistivity, b) thermopower, c) total (filled symbols) and lattice thermal conductivity (open symbols) and d) $Z T$ of the $\mathrm{K}_{2} \mathrm{Mo}_{15} \mathrm{Se}_{19}$ and $\mathrm{Ag}_{3} \mathrm{~K}_{2} \mathrm{Mo} 15 \mathrm{Se}_{19}$ compounds. The color-coded symbols are similar for all panels. In panel c), the solid horizontal black line corresponds to the estimated minimum thermal conductivity. 

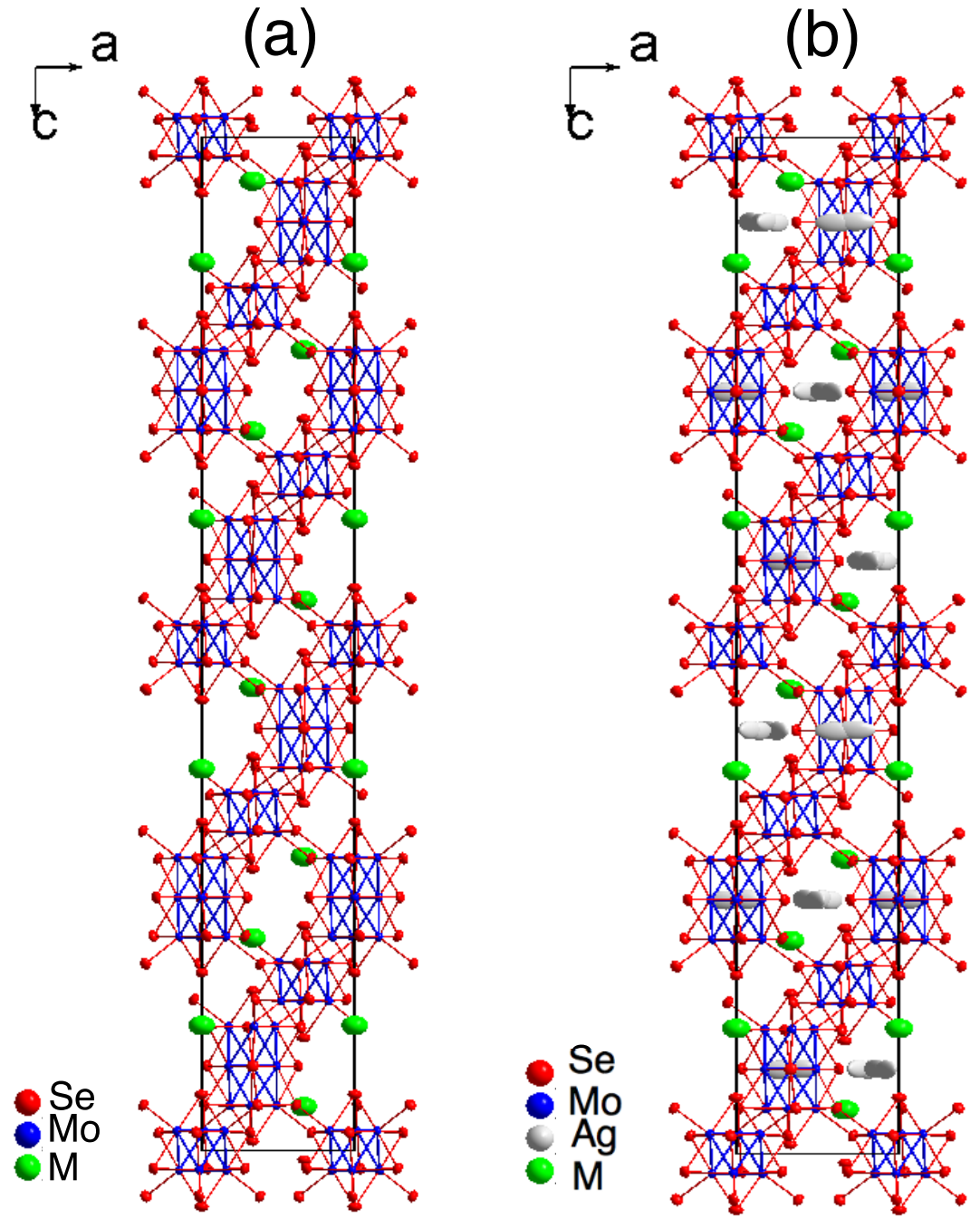

Figure 1 


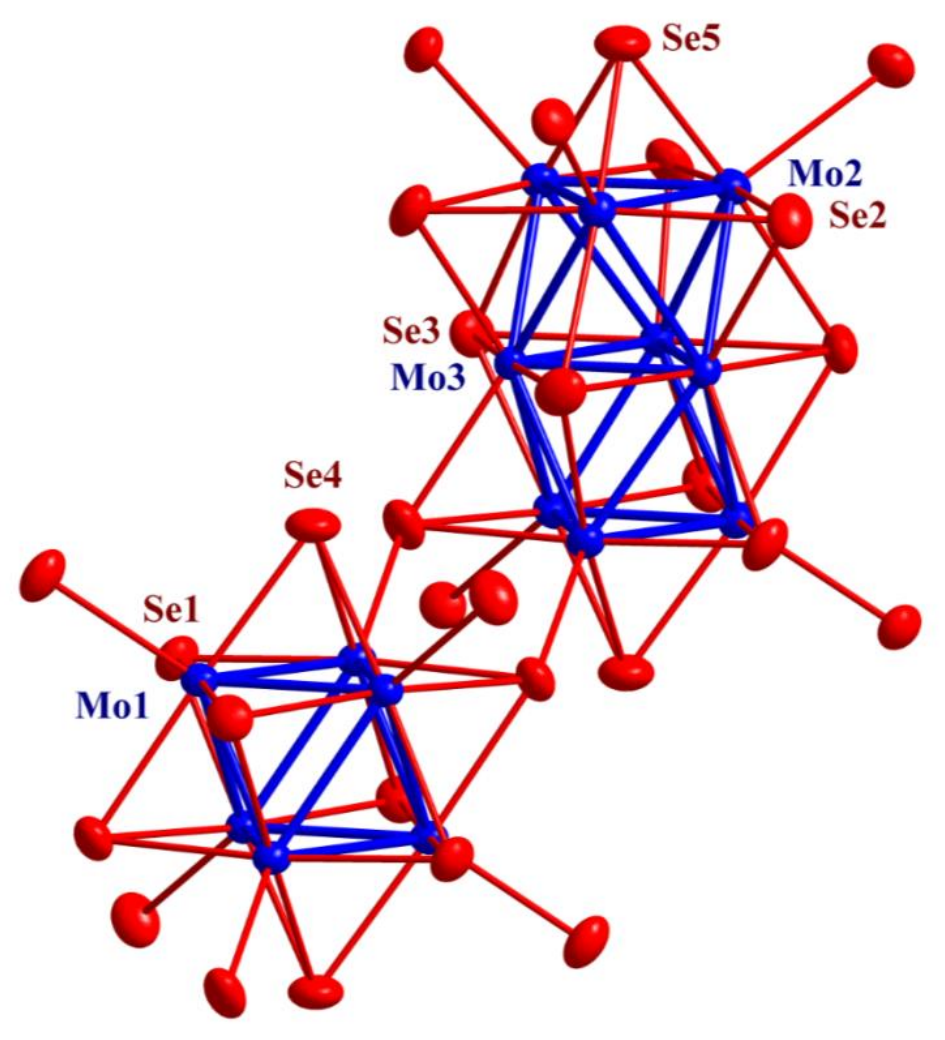

Figure 2 


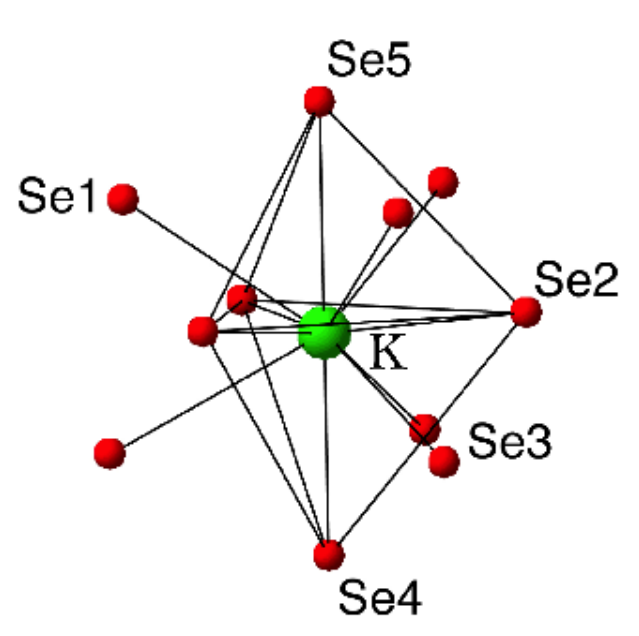

a)

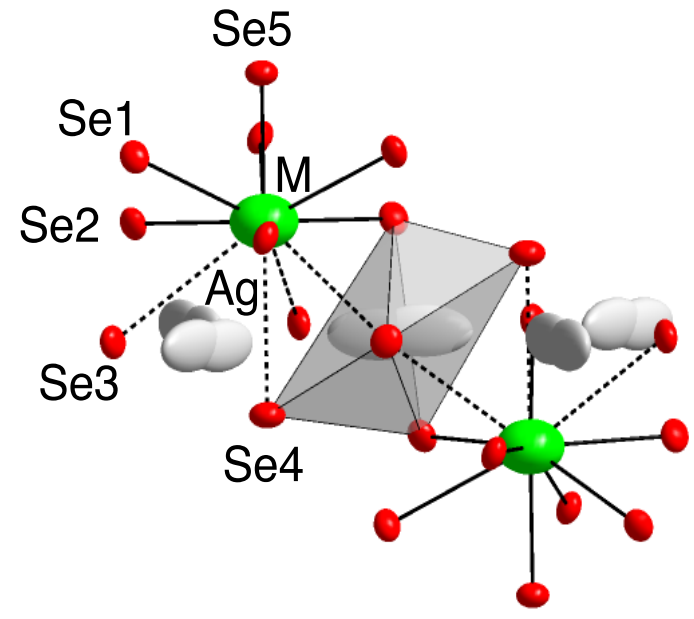

b)

Figure 3 

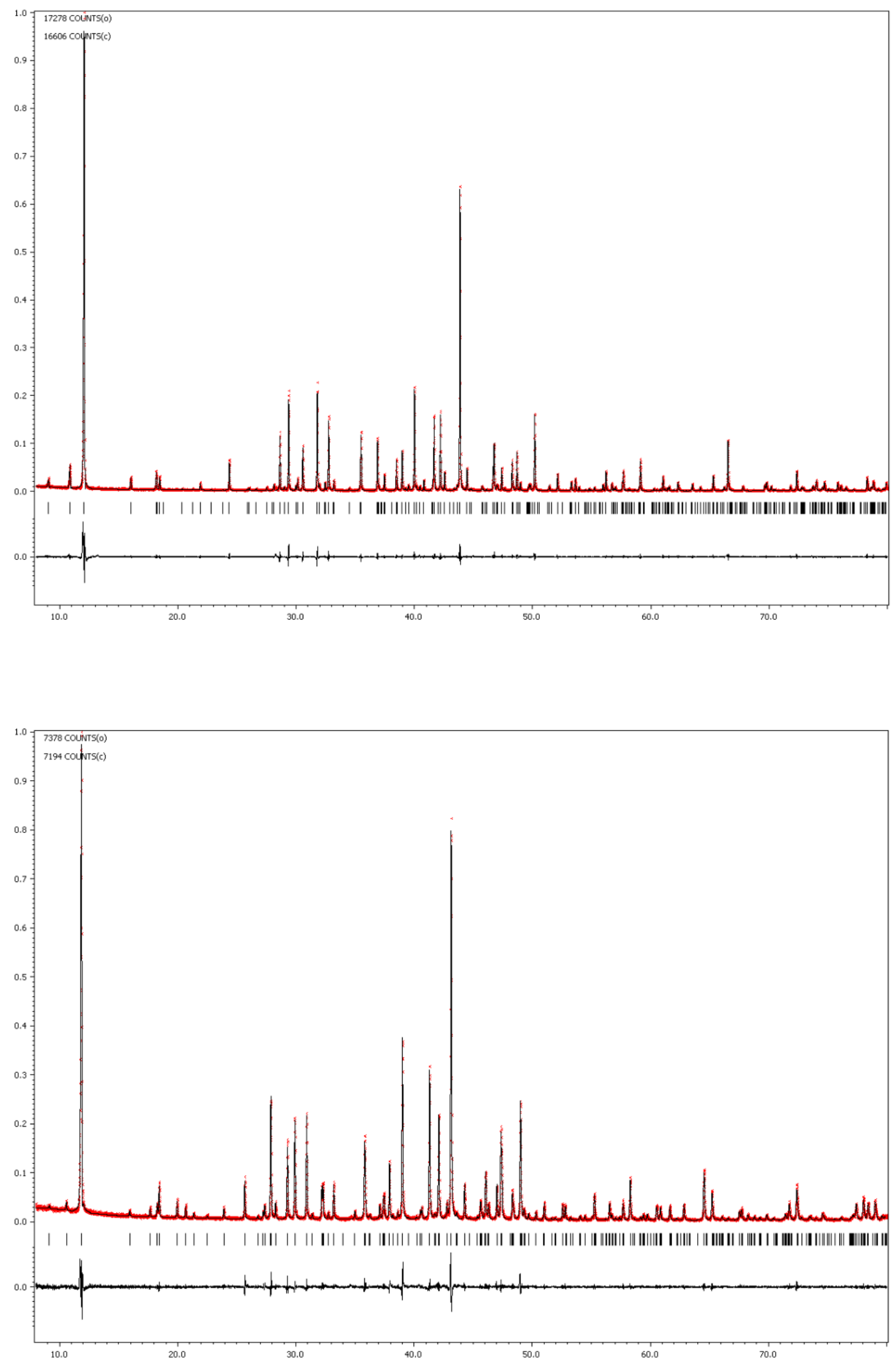

Figure 4 


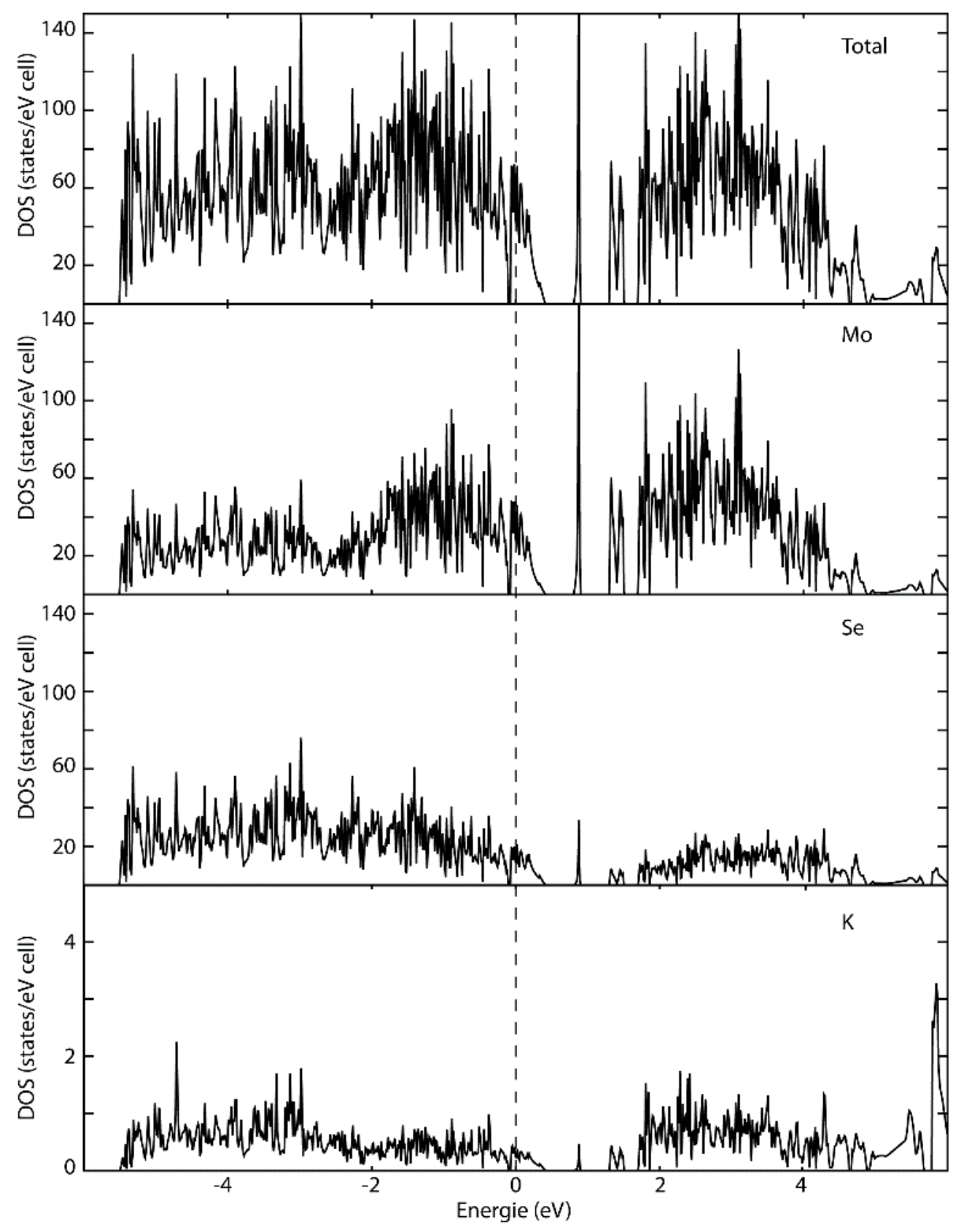

Figure 5 

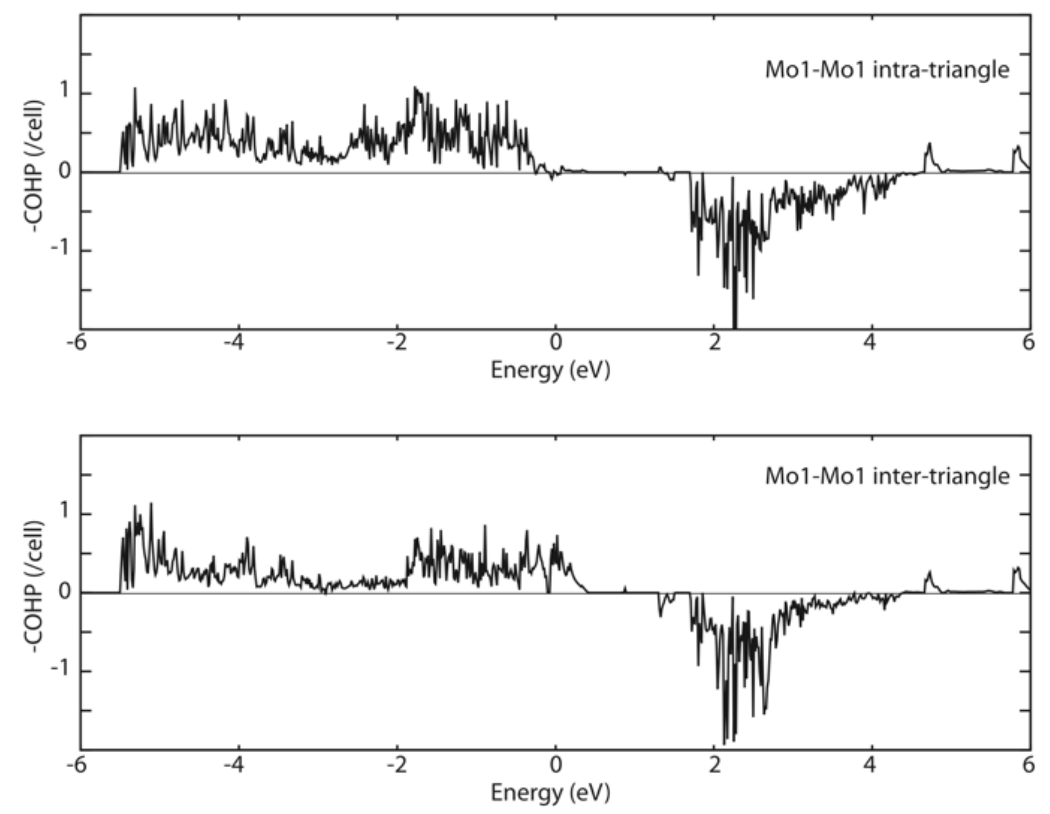

Figure 6 

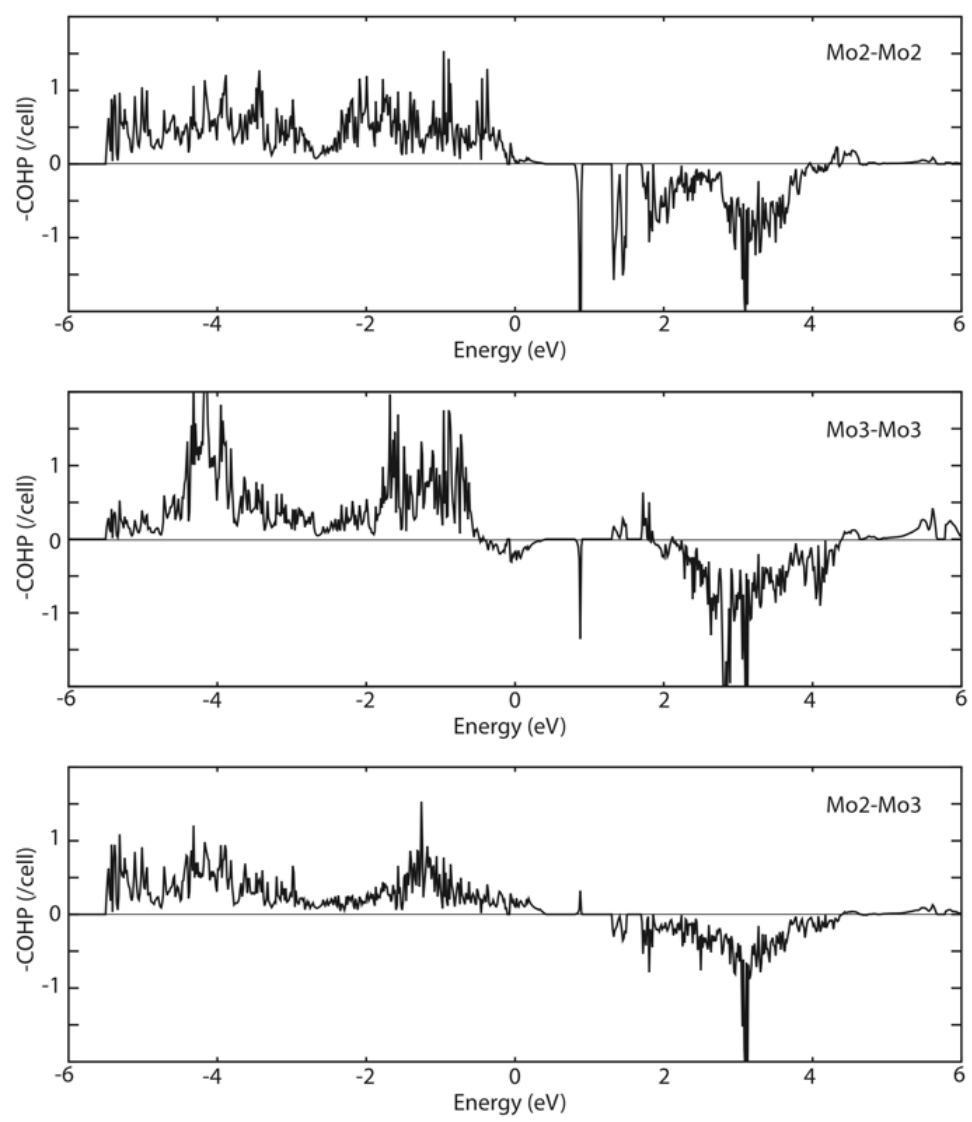

Figure 7 


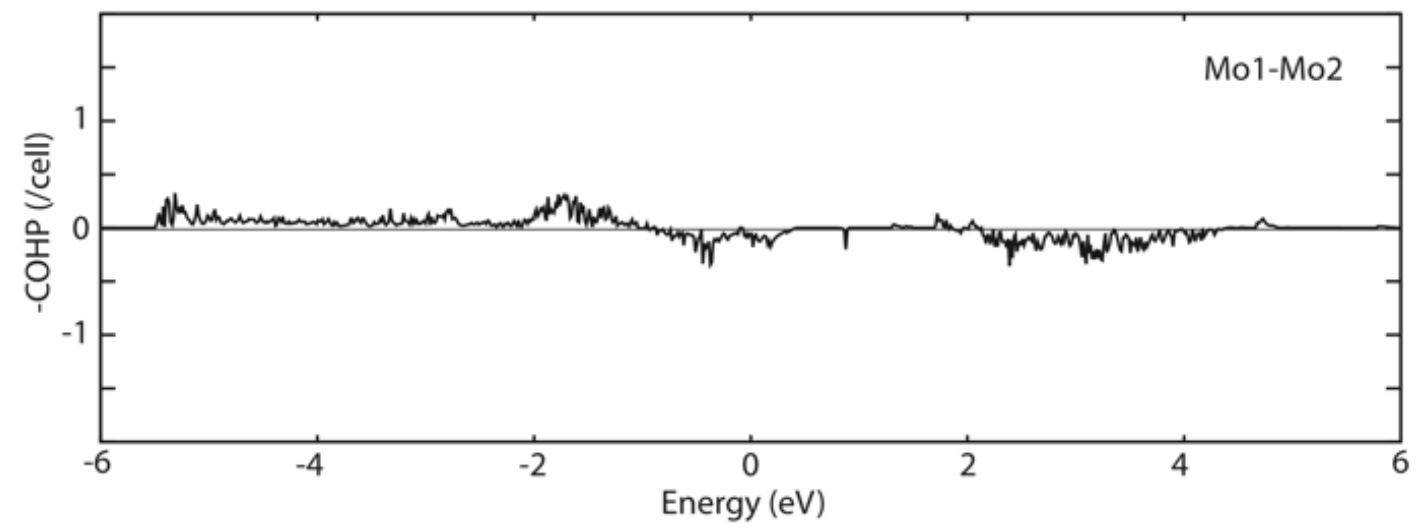

Figure 8 

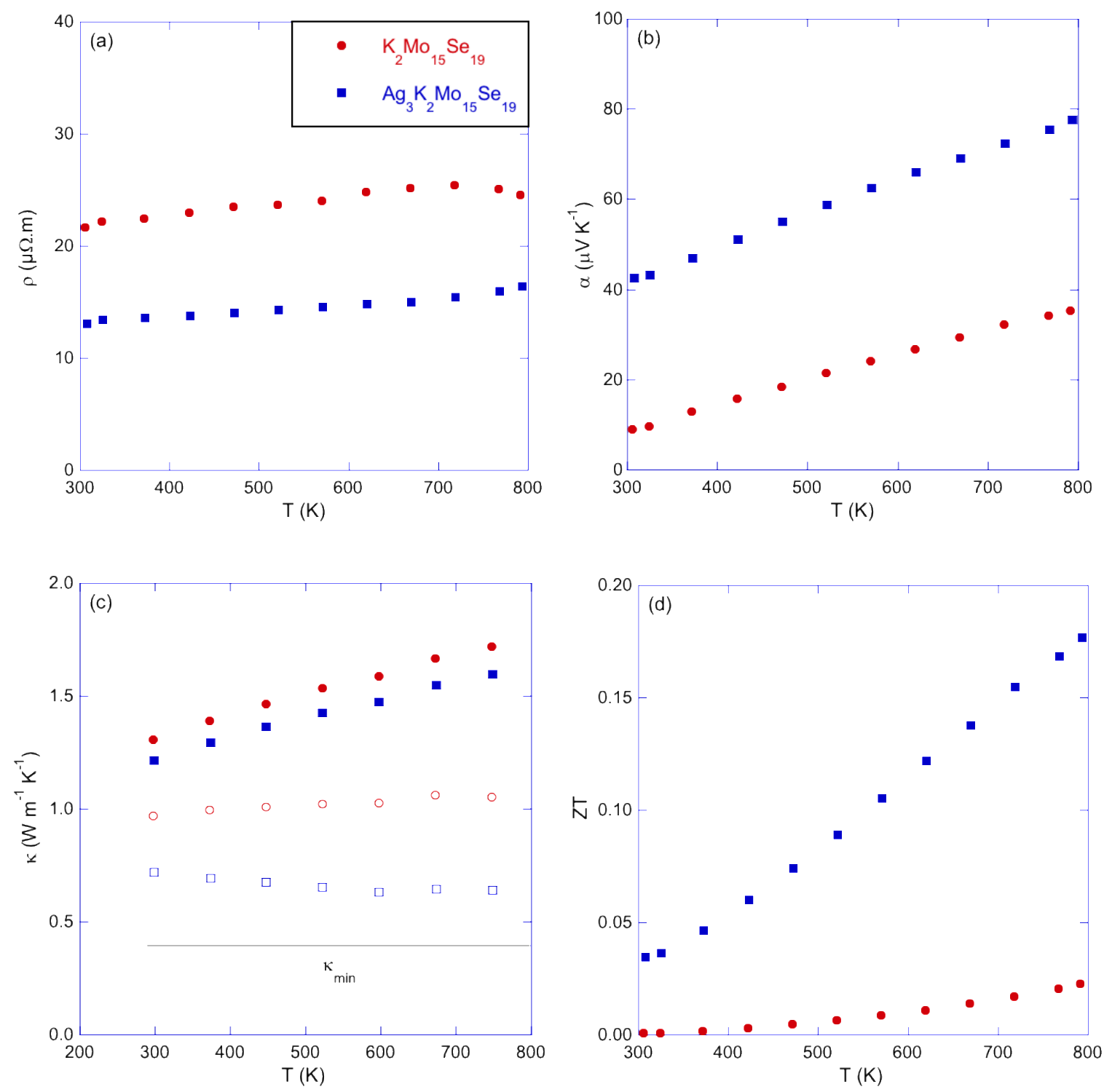

Figure 9 
Table of Contents Graphic

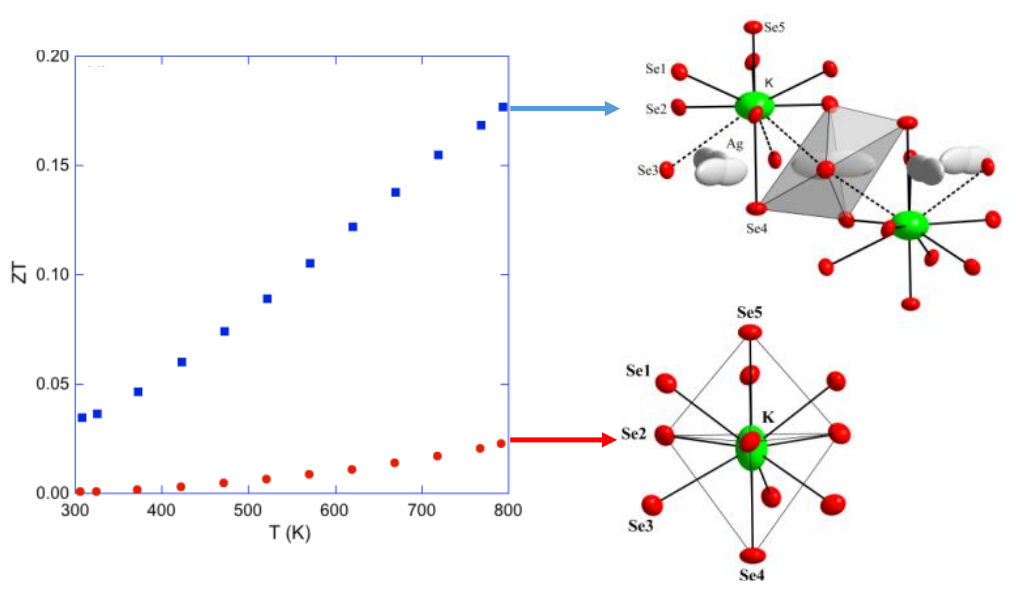

This work reports a detailed study of the influence of $\mathrm{Ag}$ insertion on the thermoelectric properties of the Mo-based cluster compound $\mathrm{K}_{2} \mathrm{Mo}_{15} \mathrm{Se}_{19}$ that yields enhanced thermoelectric properties at high temperatures. 